\title{
Profissionais e usuárias(os) adolescentes de quatro programas públicos de atendimento pré-natal da região da grande Florianópolis: onde está o pai?
}

\author{
Maria Juracy Toneli Siqueira \\ Daniela Mendes \\ Ivana Finkler \\ Thais Guedes \\ Mônica D. S. Gonçalves \\ Universidade Federal de Santa Catarina
}

\begin{abstract}
Resumo
Este artigo trata da caracterização do universo investigado em uma pesquisa sobre a estrutura e o funcionamento de quatro programas públicos de atendimento pré-natal da região da grande Florianópolis, Santa Catarina. A partir das informações obtidas através de questionários aplicados aos profissionais (34) e usuários adolescentes (63 mulheres e 6 homens), foi possível construir perfis dos grupos investigados. Os resultados indicam perfis semelhantes aos encontrados em outros programas públicos voltados para o atendimento pré-natal nesta faixa etária, nos quesitos idade, escolaridade, trabalho remunerado, número de gestações, tipo de relação com o parceiro. A exclusão do pai da arena da saúde reprodutiva permanece acontecendo em todos estes programas, à semelhança de inúmeros outros descritos pela literatura. Repensar esta situação parece urgente no sentido da construção da eqüidade de gênero neste campo, bem como no da garantia dos direitos sexuais e reprodutivos na adolescência.
\end{abstract}

Palavras-chave: Gravidez, Paternidade, Adolescência, Programas públicos, Saúde pública.

\begin{abstract}
Professionals and teenagers users of prenatal assistance in Florianopolis city and surroundings: where is the father?

This article is about the investigated universe characterization in a study about the structure and functioning of four prenatal assistance public programs of Florianópolis city (state of Santa Catarina) and surroundings. Through questionnaires applied on professionals (34) and teenagers users (63 women and six men), it was possible to build an analysis which characterized the investigated groups. The results indicate similar profiles as those found on other prenatal assistance public programs like age, scholarship, work, pregnancy occurrence and couple relationship. The father's exclusion in the reproductive health arena remains happening in all of them as well as other countless programs described on the scientific literature. To reflect upon this situation seems urgent to build gender equity in this field and also to guaranty the adolescents' sexual and reproductive rights.
\end{abstract}

Key words: Pregnancy, Fatherhood, Adolescence, Public programs, Public health.

A gravidez na adolescência tem sido motivo de preocupação crescente no âmbito das políticas públicas de saúde e educação, assim como no que concerne às organizações familiares. Este artigo apresenta resultados parciais de uma pesquisa ${ }^{1}$ mais ampla que investigou, junto a quatro programas públicos de atendimento pré-natal da região da grande Florianópolis, as concepções que profissionais e usuários produzem sobre a adolescência, incluindo a gravidez e a paternidade nesta fase do ciclo vital. Tinha-se como intuito verificar até que 
ponto as recomendações das grandes conferências promovidas pela ONU na década de 90, em especial a Conferência Internacional de População e Desenvolvimento, realizada no Cairo, em 1994, e a IV Conferência Mundial Sobre a Mulher, realizada em Beijing, em 1995², estariam sendo efetivadas no campo da saúde e direitos reprodutivos, particularmente no que diz respeito à necessidade da inclusão do homem nesta arena. Ou seja, a estrutura e o funcionamento dos programas foram investigados, bem como os atores sociais neles envolvidos, de forma a se buscar a representação do pai adolescente que circula neste âmbito, verificando se esta representação está (ou não) associada à sua inclusão/exclusão nos trabalhos ali desenvolvidos.

As instituições foram escolhidas em função de sua condição de referência na área da saúde no município de Florianópolis. É importante destacar que os quatro programas investigados são diferentes entre si, embora todos eles sejam desenvolvidos em instituições públicas de saúde conveniadas com o SUS - Sistema Único de Saúde - e atendam, expressivamente, uma clientela oriunda dos setores populacionais de baixa-renda.

O primeiro está implantado em um grande hospital geral de grande porte da região metropolitana, tendo sido criado a partir do interesse da área do Serviço Social que, constatando um alto índice de nascimento de crianças prematuras e/ou com baixo peso, filhas de mães adolescentes, buscou implantar um programa voltado à clientela gestante nessa faixa etária. Constituiu-se, para tanto, uma equipe multidisciplinar, a partir do interesse de profissionais em participar do trabalho. Neste programa são realizadas, além das consultas de rotina, reuniões quinzenais com grupos de gestantes e puérperas adolescentes, coordenadas, em geral, por uma assistente social ou uma enfermeira.

Outro programa investigado é desenvolvido em uma maternidade, também de grande porte, que já funcionou como maternidade escola da Universidade Federal de Santa Catarina. Nesta instituição, o atendimento pré-natal de adolescentes é de responsabilidade de uma médica ginecologista-obstetra e sua equipe de residentes. Dife- rentemente do anterior, nesse programa não há reuniões de grupo, sendo as atividades limitadas às consultas de rotina pré-natal.

O terceiro programa pertence ao hospital da Universidade Federal de Santa Catarina e não conta com qualquer serviço especializado para adolescentes. Neste caso, as gestantes nessa faixa etária são atendidas no ambulatório geral de ginecologia e, quando o aceitam, em reuniões grupais que incluem mulheres grávidas de todas as idades, distribuídas em dois projetos específicos: "Grupo de gestantes e/ou casais do terceiro ao sétimo mês" e "Grupo de gestantes do terceiro trimestre". Estas reuniões são coordenadas por profissionais da área da enfermagem e/ou da psicologia.

Finalmente, o último programa pertence à Policlínica de Referência Regional onde foi implantado o PROSAD Programa de Saúde do Adolescente - do governo federal. Uma equipe multiprofissional é encarregada das atividades, sendo que a rotina dos atendimentos pré-natais centra-se nas consultas sob a responsabilidade de uma médica ginecologista-obstetra e, esporadicamente, em grupos de sala de espera coordenados por uma enfermeira. Em um programa mais amplo, no entanto, são realizados encontros grupais semanais com adolescentes de ambos os sexos divididos segundo a faixa etária, não sendo específicos para gestantes.

Com o intuito de conhecer a estrutura e o funcionamento destes programas, foram realizadas observações participantes das salas de espera e das reuniões de grupos de gestantes - quando existiam -, além de consultas a documentos (projetos de implantação, PROSAD, relatórios, entre outros), assim como foi aplicado um questionário misto aos profissionais e aos usuários do serviço. O questionário constituía-se de uma parte introdutória de identificação, composta por questões de caráter demográfico, bem como de duas outras seções voltadas para os temas gravidez e programa de atendimento prénatal. Obteve-se um total de 34 questionários de profissionais, 63 de gestantes adolescentes e seis de pais adolescentes $^{3}$. O presente artigo é baseado no resultado das questões de caráter demográfico que permitiram traçar um perfil dos três grupos investigados, associado a da-

Tabela 1. Distribuição das adolescentes por faixa etária

\begin{tabular}{lcr}
\hline Faixa etária (anos) & N & $\%$ \\
\hline $13-15$ & 14 & 22,20 \\
$16-18$ & 41 & 65,10 \\
19 & 08 & 12,7 \\
Total & 63 & 100 \\
\hline
\end{tabular}

Fonte: Dados obtidos junto a usuárias dos programas investigados. 
Tabela 2. Distribuição das usuárias adolescentes por condição escolar e trabalho remunerado

\begin{tabular}{lrrrr}
\hline & Estuda & Estuda & Trabalha & Trabalha \\
\hline Respostas & $\mathrm{n}$ & $\%$ & $\mathrm{~N}$ & $\%$ \\
\hline Sim & 14 & 22,2 & 12 & 19,0 \\
Não & 49 & 77,8 & 51 & 81,0 \\
Total & 63 & 100 & 63 & 100 \\
\hline
\end{tabular}

Fonte: Dados obtidos junto a usuárias dos programas investigados.

dos obtidos através das observações realizadas nos locais onde eram desenvolvidas as atividades.

Os perfis aqui apresentados foram obtidos através de uma análise simples de freqüência e têm um caráter descritivo. Os dados foram coletados através dos questionários aplicados nas salas de espera ou em outro local da instituição onde as gestantes estivessem reunidas. Todos os profissionais efetivos das equipes encarregadas dos programas foram entrevistados. Das adolescentes usuárias no período de três meses (agosto a outubro de 1999), poucas foram as que se recusaram a participar da pesquisa e, portanto, atingiu-se praticamente todo o universo de usuárias no trimestre. Não se abordou as que passaram exclusivamente pela maternidade para o parto. Dos rapazes, conseguiu-se entrevistar apenas seis, em função de dois motivos principais: primeiro, as gestantes, em sua grande maioria, comparecem às consultas sozinhas ou acompanhadas de outras mulheres - mãe, avó, amiga. Muitas delas alegaram que o pai da criança estava trabalhando naquele horário (período comercial) e, portanto, impossibilitado de comparecer. Segundo, na maior parte dos casos, a idade do pai extrapolava a faixa da adolescência. Sabendo inexpressivo o número obtido, não foi possível realizar análises mais consistentes, nem considerar o grupo representativo dos parceiros das gestantes que freqüentam estes programas.

\section{Perfil das adolescentes investigadas}

Com relação à idade, observa-se uma maior concentração destas jovens na faixa dos 16 aos 18 anos, conforme se pode observar na Tabela 1. Estes dados corroboram o que outras pesquisas no âmbito da América Latina vêm encontrando com relação à distribuição da incidência da gravidez na adolescência conforme a faixa etária das mães (BEMFAM, 1999; Costa, Pinho \& Martins, 1995; Meacham, 1996).

A maioria destas adolescentes deixou de estudar e não exerce qualquer atividade remunerada. No entanto, $22,2 \%$ delas estudam e $19 \%$ trabalham, o que é um número ainda expressivo considerando-se que, via de regra, a gravidez na adolescência colabora sobremaneira para o abandono da escola e/ou do trabalho remunerado (BEMFAM, 1999).

Segundo a PNDS/1996 (BEMFAM, 1999) $)^{4}, 69,3 \%$ das adolescentes investigadas, na faixa etária de 15 a 19 anos, continuavam freqüentando a escola. Das que a abandonaram, 5,6\% alegaram que precisavam trabalhar. Identificou-se, ainda, que 3,9\% alegaram o fato de terem engravidado e $2,2 \%$ o de terem se casado. Constata-se, portanto, que além do fator econômico, a gravidez e o casamento configuram-se como motivos para o abandono da escolarização. Na presente pesquisa, no entanto,

Tabela 3. Distribuição das adolescentes por nivel de escolaridade

\begin{tabular}{lcr}
\hline Nível de escolaridade & N & $\%$ \\
\hline Ensino fundamental incompleto & 32 & 50,80 \\
Ensino fundamental completo & 09 & 14,30 \\
Ensino médio incompleto & 09 & 14,30 \\
Ensino médio completo & 12 & 19,00 \\
Não respondeu & 01 & 1,60 \\
Total & 63 & 100 \\
\hline
\end{tabular}

Fonte: Dados obtidos junto a usuárias dos programas investigados. 
68 M.J.R. Siqueira et al

Tabela 4. Distribuição das adolescentes segundo o tipo de relação que mantêm com o pai da criança

\begin{tabular}{lrr}
\hline Tipo de relação & $\mathrm{N}$ & $\%$ \\
\hline Não mantêm a relação amorosa & 6 & 9,52 \\
Mantêm a relação amorosa mas não moram juntos & 9 & 14,29 \\
Moram juntos e não são casados & 26 & 41,27 \\
Moram juntos e são casados & 19 & 30,16 \\
Não o viu mais & 2 & 3,17 \\
Não respondeu & 1 & 1,59 \\
Total & 63 & 100 \\
\hline
\end{tabular}

Fonte: Dados obtidos junto a usuárias dos programas investigados.

não se tem a informação de que o abandono foi ocasionado pela gravidez. Nas camadas populares brasileiras, a taxa de evasão escolar é alta e multicausal. Dentre os elementos que a engendram pode-se mencionar tanto os de ordem sócio-econômica como a necessidade de trabalhar -, quanto aqueles oriundos do próprio sistema educacional - como a inadequação da escola à sua clientela (Patto, 1990). Trata-se de uma problemática crônica, de difícil resolução, que perceptível pelos altos índices de repetência nestes setores da população. Verifica-se que a tendência nestes segmentos é o abandono precoce do processo de escolarização, em especial no caso dos meninos, tanto pela necessidade de trabalhar, quanto pela maior incidência de reprovações. Esta tendência é constatada, por exemplo, pela mesma PNDS/96 (BEMFAM, 1999).

Conforme se pode verificar na Tabela 3, metade das adolescentes investigadas possui, como nível de escolaridade, apenas o do ensino fundamental incompleto $(50,8 \%)$, dado que, analisado juntamente com os anteriores, configura uma situação de baixo nível de escolarização destas adolescentes.

Das que mantêm relação amorosa com o pai da criança, $30,16 \%$ casaram-se oficialmente e $41,27 \%$, embora não tenham legalizado a relação, moram com o parceiro e a ele se referem como "marido". Há, portanto, um número muito significativo destas adolescentes $(71,43 \%)$ que man- tém a relação com o pai da criança, inclusive com ele coabitando.

Estas jovens moram com o pai da criança e/ou com seus próprios pais. Pode-se levantar a hipótese de que, mesmo aquelas que não estudam e/ou trabalham de forma remunerada, exercem alguma atividade no âmbito da casa, ou seja, auxiliam na lida doméstica, embora não se tenha esta questão explicitada no questionário. Esta hipótese é possível face aos estudos sobre as camadas populares, nas quais as crianças e os jovens, ainda que não exerçam atividade remunerada, são responsáveis por tarefas como cuidar dos irmãos menores, da casa, da alimentação. Vê-se aqui a manutenção do papel tradicional atribuído à mulher, o que pode ser corroborado pelas respostas dos adolescentes de ambos os sexos, apontando que a maior responsabilidade do pai é a de sustentar a mãe e a criança, cabendo à mãe a maior responsabilidade pela educação dos filhos (Afonso, 2001; Arilha, Ridenti \& Medrado, 1998; Bilac \& Rocha, 1998; Costa,1997; Fuller, 2000; Pantelides, Geldstein \& Domínguez,1995; Pantelides $\&$ Bott, 2000). Estas jovens residem, em sua maioria, no município de Florianópolis ou naqueles que compõem a grande região metropolitana (Palhoça e São José, principalmente).

Além disso, o maior número destas gestantes adolescentes está vivenciando sua primeira gravidez $(90,5 \%)$, conforme a Tabela 5 permite-nos constatar.

Tabela 5. Distribuição das adolescentes quanto ao número de gestações

\begin{tabular}{lrr}
\hline $1^{\text {a }}$ Gestação & $\mathrm{n}$ & $\%$ \\
\hline Sim & 57 & 90,50 \\
Não & 06 & 9,50 \\
Total & 63 & 100 \\
\hline
\end{tabular}

Fonte: Dados obtidos junto a usuárias dos programas investigados. 
Tabela 6. Distribuição dos profissionais por faixa etária

\begin{tabular}{lrr}
\hline Faixa etária (anos) & $\mathrm{n}$ & $\%$ \\
\hline $21-30$ & 04 & 11,77 \\
$31-40$ & 18 & 52,94 \\
$41-50$ & 11 & 32,35 \\
$51-60$ & 01 & 2,94 \\
Total & 34 & 100 \\
\hline
\end{tabular}

Fonte: Dados obtidos junto aos profissionais dos programas investigados.

\section{Perfil dos profissionais investigados}

Quanto aos 34 profissionais entrevistados, a faixa etária de maior concentração é a de 31 a 40 anos (52,94\%), seguida de $32,35 \%$, na faixa de 41 a 50 anos (Tabela 6). Estes dados permitem pensar que se trata de profissionais que já têm alguma experiência acumulada, sobretudo quando associados ao tempo de serviço e ao fato de que o acesso a estes programas ocorre através de concursos públicos que, há muito, vêm escasseando no país.

Conforme a Tabela 7 permite verificar, $88,23 \%$ dos profissionais contatados são do sexo feminino. Identifica-se, novamente, a predominância de mulheres em programas cuja atividade principal é a de cuidar, mantendo a territorialização ocupacional por sexo/gênero. A história do hospital evidencia esta distribuição desde o seu início, embora de forma desigual no que diz respeito aos lugares/posições que os atores sociais ocupam nesta instituição. Antes mesmo dos médicos, em geral do sexo masculino, entrarem nessa instituição, as mulheres faziam caridade cuidando dos doentes, isto é, fazendo algo que é atribuído "naturalmente" ao sexo feminino. A área de saúde reprodutiva, por sua vez, pode ser considerada um território feminino dentre um universo maior que é o da saúde, face à associação histórica entre a mulher e a maternidade.

Deve-se considerar, também, que, mesmo em equipes multidisciplinares, a figura que ocupa o lugar do topo da hierarquia é, em geral, o médico a quem cabem as decisões fundamentais. Entretanto, faz-se importante ressaltar que, nos programas investigados exclusivamente voltados para adolescentes, a coordenação era exercida por mulheres com formações distintas - uma enfermeira e outra assistente social. Os profissionais de outras áreas permanecem, em geral, mais tempo diário na instituição, ao passo que os médicos ali comparecem apenas em determinados horários. O período diário de permanência no local favorece o contato com a clientela e com os companheiros de trabalho, sendo difícil para os médicos integrarem-se genuinamente à equipe, o que pôde ser constatado, inclusive, pela dificuldade de se entrevistar estes profissionais.

Em relação à função exercida pelos profissionais, pode-se notar um número expressivo de médicos, um terço do total, o que não causa estranheza em função do lugar social ocupado por esta categoria nos setores de saúde, qual seja, o de figura principal das equipes. No entanto, dois terços do total de profissionais possuem outra formação, o que é significativo, no sentido da constituição de equipes multidisciplinares. Este dado é relevante, posto que, se nas instituições de saúde a figura principal é a do médico, sendo considerado ainda o hospital o lugar de poder desses profissionais, há, no entanto, um esforço no sentido da composição das equipes, de forma a contemplar visões distintas oriundas de campos disciplinares diferentes. Estas formações incluem as áreas da enfermagem, do serviço social, da psicologia, da fisioterapia, da sociologia e da pedagogia, em geral ocupadas por profissionais do sexo feminino.

Ao analisar ainda as funções exercidas, chama a atenção que, dentre os médicos, somente três são homens. De certa forma, este resultado era esperado pois, entre as mulheres que exercem a medicina, a grande maioria está

Tabela 7. Distribuição dos profissionais por sexo

\begin{tabular}{lrr}
\hline Sexo & $\mathrm{n}$ & $\%$ \\
\hline Feminino & 30 & 88,23 \\
Masculino & 04 & 11,77 \\
Total & 34 & 100 \\
\hline
\end{tabular}

Fonte: Dados obtidos junto aos profissionais dos programas investigados. 
concentrada nas áreas de gineco-obstetrícia e pediatria, exatamente as especialidades dos médicos que participam dos programas. Outro dado relevante é que existe em um dos programas que possui equipe multidisciplinar, um homem trabalhando na área de pedagogia, considerada historicamente de atuação feminina. Importante considerar, também, que, em um dos programas investigados, as atividades são desenvolvidas por uma médica e seus residentes, com o apoio de uma enfermeira e uma técnica em enfermagem. Neste caso, não há genuinamente uma equipe multidisciplinar constituída, situação agravada ainda pelo fato de que os residentes permanecem ali apenas durante um mês, na medida em que devem transitar por todos os setores da instituição.

\section{Perfil dos adolescentes investigados}

Quanto aos seis rapazes, encontram-se na faixa dos 17 aos 19 anos de idade sendo que quatro deles possuem o nível fundamental completo de escolaridade e apenas um, o nível médio completo. Somente um permanece estudando e três exercem algum tipo de atividade remunerada. Há uma dispersão quanto ao município onde moram, embora se mantenham na região da grande Florianópolis. Esta dispersão aparece, também, no que diz respeito a com quem moram, incluindo organizações familiares diferentes: pai-mãe-filhos, mãe-filhos, pai-mãeavó-filhos, mãe-avó-filhos, irmãos apenas. Esta dispersão parece retratar a multiplicidade de organizações familiares contemporâneas e destaca-se dado o número restrito de jovens do sexo masculino entrevistados. Todos eles estão vivenciando pela primeira vez a gravidez de uma parceira.

O número extremamente reduzido de rapazes entrevistados, em comparação com o das gestantes, deve-se maciçamente à ausência dos pais nos programas investigados. Observa-se aqui, ainda, uma aparente contradição com o quê os profissionais e os próprios usuários afirmam sobre a inadequação dos horários das reuniões e consultas, que acontecem no período comercial, e, portanto, são pouco favoráveis à inclusão do pai. Três dos rapazes entrevistados não trabalham e, destes, dois sequer estudam. Este fato constatado não invalida, no entanto, a hipótese, confirmada inclusive pelas adolescentes e pelos profissionais, de que o trabalho é um fator que dificulta a vinda do jovem, uma vez que o grupo investigado é muito reduzido e pouco representativo do universo de pais adolescentes em geral. Importante destacar, como já mencionado, que daqueles que compareceram às instituições, a maioria abordada já havia saído da faixa da adolescência, o que vem ao encontro dos resultados de outras pesquisas que apontam uma discrepância entre a idade da mãe e a do pai ainda existente contemporaneamente (BEMFAM, 1999; Costa, Pinho \& Martins, 1995).

Como o objetivo da pesquisa era o de investigar se e como estes programas incluem o pai adolescente, dos poucos pais que efetivamente compareciam às instituições acompanhando suas parceiras, apenas esses seis, no trimestre, corresponderam à faixa etária. Portanto, restringiu-se, sobremaneira, a possibilidade de se traçar um genuíno perfil dos pais adolescentes.

\section{Discussão dos resultados}

Como já anunciado na descrição dos resultados da análise quantitativa dos dados obtidos, pode-se constatar que estes adolescentes são, em termos demográficos, semelhantes a inúmeros outros que freqüentam os serviços públicos de saúde no Brasil. Mais do que isto, podese constatar que a grande maioria destes jovens comparece ao programa apenas quando suspeitam que algo "errado" está acontecendo com eles. De fato, no âmbito do senso comum e, mesmo no das práticas discursivas médico-científicas, a gravidez na adolescência é vista como um problema. Os argumentos oscilam entre aspectos de ordem da saúde física da mãe e do bebê, aspectos de ordem de uma "imaturidade emocional", aspectos de ordem econômico-social como o "destino" destas jovens que criarão seus filhos sozinhas e/ou o abandono da escolaridade formal e as dificuldades maiores em sua inserção no mercado de trabalho assalariado.

Pode-se argumentar, no entanto, que, em especial, no que diz respeito aos segmentos populacionais de baixa-renda, a evasão escolar é alta, existindo ou não uma gravidez na adolescência desses jovens jovens. A qualificação para o mercado de trabalho é precária, já que muitos desses adolescentes lutam pela sobrevivência fora de suas casas desde cedo, assim como nelas também assumem tarefas como cuidar dos irmãos menores, cozinhar, limpar a casa, e assim por diante.

No que diz respeito aos adolescentes investigados, a maior parte deles declarou, na seção específica do questionário, que quiseram engravidar (inclusive os rapazes). No entanto, este "querer" não é problematizado pelos programas investigados, ainda que implique em motivos de ordens as mais diversas, até mesmo aquelas relativas ao âmbito dos processos de identificação e idealização imaginária. Parte-se do suposto de que a gravidez é indesejada, inconseqüente, fruto da irresponsabilidade, da imaturidade e da impulsividade destes jovens. Por quê a gravidez na adolescência é assim significada na contemporaneidade? Várias hipóteses 
podem ser elaboradas a este respeito. Algumas delas podem estar relacionadas exatamente com o pai da criança.

Pode-se argumentar, por exemplo, que a gravidez na adolescência parece ter sido significada como problemática ou como um problema social à medida que a idade do pai coincidiu com essa fase do ciclo vital. Por que? Uma das respostas possíveis talvez esteja associada à tradicional divisão sexual do trabalho que delega aos homens a função de prover a família. Como um adolescente, sem qualquer qualificação profissional, poderá ser provedor? A paternidade na adolescência engendra, então, um ônus a mais para o Estado e para as famílias de origem, que se vêem às voltas com o sustento de mais um membro no grupo familiar. $\mathrm{O}$ ônus para o Estado recai na necessidade de mais vagas nos serviços públicos de saúde e nas instituições escolares, bem como em políticas públicas de geração de renda e apoio às famílias dos setores de baixa-renda.

Muitas dessas jovens não comparecem sequer mensalmente nas instituições para as consultas de rotina do atendimento pré-natal. As que o fazem, via de regra, não conseguem acesso a setores mais especializados, incluindo exames como a ecografia, em tempo hábil para o acompanhamento eficaz da gestação.

$\mathrm{O}$ espaço físico destinado aos programas investigados é exíguo, implicando em salas de espera lotadas, nas quais, em algumas situações, um dos profissionais freqüentemente uma enfermeira - dá orientações gerais sobre o processo de gestação.

Observou-se, com relação aos rapazes entrevistados, que os poucos homens que ali se encontravam, permaneciam na sala de espera aguardando a parceira. Apenas um deles não demonstrou vontade de acompanhá-la na consulta. Todos os outros manifestaram interesse em estarem mais próximos, acompanhando a gestação do filho. Ouvir o coração do bebê parece ser um desejo unânime desses rapazes. Este desejo talvez esteja associado à materialização da criança que, antes dessas manifestações, era apenas intuída pelo pai através das informações obtidas da mãe. A despeito de tudo isto, no entanto, esses homens não são convidados pelos programas, não fazem parte da rotina de suas atividades e, aqueles poucos que aguardavam na sala de espera, não foram convidados sequer para adentrarem à sala de consulta.

A presença maciça de mulheres, tanto nas equipes profissionais quanto no grupo de usuários, demonstra bem a associação entre a saúde reprodutiva e as mulheres. Mesmo as gestantes adolescentes, embora expressando um desejo de que seus parceiros as acompanhassem, compareciam às consultas, em geral, com suas mães ou outras mulheres. A grande maioria delas, permanece com o pai do bebê, o que, com relação ao grupo investigado, não confirma a tese dos profissionais sobre o término da relação amorosa e/ou o abandono da mãe pelo pai da criança. $O$ fato de muitas não se casarem através de contrato civil ou religioso não destoa significativamente da tendência contemporânea da diminuição do número de casamentos. Em se tratando de segmentos de baixa-renda, esta situação sempre esteve presente.

A gravidez na faixa dos 13 aos 19 anos também era freqüente há algumas décadas em todos as camadas sociais, uma vez que as mulheres casavam-se cedo e tornavam-se mães logo após a menarca. O que parece ter se modificado é a idade dos pais, pois há mais adolescentes tornando-se pais do que acontecia anteriormente, já que a diferença etária entre os parceiros era acentuada. Esta diferença ainda permanece existindo, como esta própria pesquisa permite deduzir, mas aumentou o número de adolescentes do sexo masculino que se tornam pais.

$\mathrm{O}$ que aparece de forma mais significativa é exatamente a exclusão do jovem pai das atividades previstas pelos programas. Os profissionais argumentam que os pais não são atuantes e que, em sua maioria, abandonaram a parceira, o que esta pesquisa não confirma.

Lembrando que as recomendações sobre a inclusão dos homens na arena reprodutiva têm como um de seus objetivos a construção da eqüidade de gênero, esta clientela adolescente precisa ser considerada e incluída nos trabalhos desenvolvidos. Trata-se de uma oportunidade ímpar de se discutir, com esses jovens, questões como as relações de gênero no cotidiano do casal e da família, a distribuição mais eqüitativa de responsabilidades entre o casal, a negociação da contracepção, os direitos reprodutivos, entre tantas outras, que poderiam significar uma contribuição para a constituição de sujeitos mais autônomos, mais solidários e, ao mesmo tempo, mais críticos. Neste sentido, trata-se de colaborar mais efetivamente para o exercício dos direitos reprodutivos no que diz respeito à cidadania no âmbito da vida pública, bem como no da vida privada. $\mathrm{O}$ caráter educativo que os serviços de saúde podem engendrar assume uma especial importância no sentido não apenas da melhoria da qualidade da vida, no sentido restrito do não adoecer. Os adolescentes estão exatamente na fase de transição entre o mundo da infância e o mundo adulto no qual a constituição das relações amorosas e sexuais assume um lugar de destaque. A desnaturalização dos modelos preconceituosos/estereotipados sobre o masculino e o feminino é fundamental para a constituição de relações mais igualitárias entre os sexos. Considerando-se, ainda, o papel multiplicador dos agentes de saúde e educação, urge discutir estas 
questões com os profissionais que trabalham na área para que as diretrizes firmadas formalmente no papel possam, de fato, ser implementadas.

Finalmente, é de fundamental importância a discussão sobre as políticas públicas voltadas para os adolescentes. Destacam-se, sobretudo, aquelas voltadas para a educação, a saúde, o trabalho/profissionalização, a cultura e o lazer, uma vez que a saúde sexual e reprodutiva não pode ser pensada de forma desarticulada das demais.

\section{Referências}

Afonso, L. (2001). A polêmica sobre adolescência e sexualidade. Belo Horizonte: Campo Social.

Arilha, M., Ridenti, S., \& Medrado, B. (Orgs.). (1998). Homens e masculinidades: outras palavras. São Paulo: ECCOS/Editora 34.

BEMFAM. Sociedade Civil Bem-estar Familiar no Brasil. (1999). Adolescentes, jovens e a Pesquisa Nacional sobre Demografia e Saúde. Um estudo sobre fecundidade, comportamento sexual e saúde reprodutiva. Rio de Janeiro: Autor.
Bilac, E. D. , \& Rocha, M. I. B. (Orgs.), Saúde reprodutiva na América Latina e no Caribe: temas e problemas (pp. 237-260). Campinas: Editora 34.

Costa, A. (Org.). (1997). Direitos tardios. Saúde, sexualidade e reprodução na América Latina. São Paulo: Prodir/FCC/Editora 34.

Costa, M. C. O., Pinho, J. F. C., \& Martins, S. J. (1995). Aspectos psicossociais e sexuais de gestantes adolescentes em Belém-Pará. Jornal de Pediatria, 71, 151-157.

Fuller, N. (Org.) (2000). Paternidades en América Latina. Lima: Pontificia Universidad Católica del Perú.

Meacham, D. (1996). Sexualidad y salud reproductiva de adolescentes. El desafio del 2000. Revista Mujer Salud, 4, 30-54.

ONU. Organização das Nações Unidas. (1996). IV Conferência Mundial sobre a Mulher. Rio de Janeiro: FIOCRUZ.

Pantelides, E. A. \& Bott, S. (Orgs.). (2000). Reproducción, salud y sexualidad en América Latina. Buenos Aires: Biblos/OMS.

Pantelides, E. A., Geldstein, R. N. \& Domínguez, G. I. (1995). Imagenes de genero y conducta reproductiva en la adolescencia. Buenos Aires: CENEP.

Patto, M. H. S. (1990). A produção do fracasso escolar. São Paulo: T. A. Queiroz.

\section{Notas}

1 Pesquisa financiada pelo PRODIR III - Programa de Treinamento em Pesquisa sobre Direitos

Reprodutivos - Fundação MacArthur/Fundação Carlos Chagas, com bolsas PIBIC/CNPq/UFSC e apoio do Funpesquisa/UFRSC.

2 O conceito de saúde reprodutiva aqui utilizado é o proposto nesta última conferência (ONU, 1996, p. 77).

3 Adotou-se, nesta pesquisa, a faixa etária estipulada pela Organização Mundial da Saúde (OMS) para a adolescência, 10 a 19 anos.

$4 \quad$ Esta pesquisa tem um caráter de referência nacional, no que diz respeito ao comportamento sexual e reprodutivo dos adolescentes brasileiros.

Maria Juracy Toneli Siqueira, doutora em Psicologia Escolar e do Desenvolvimento Humano pela Universidade de São Paulo, SP, é Professora Adjunta do Departamento de Psicologia da Universidade Federal de Santa Catarina, SC.

Daniela Mendes, Ivana Finkler e Thais Guedes são bolsistas IC/CNPq e PIBIC/CNPq/UFSC.

Mônica D. S. Gonçalves é mestranda em Psicologia na Universidade Federal de Santa Catarina, SC. Endereço para correspondência: Universidade Federal de Santa Catarina, Campus Universitário Trindade, 88040-970, Florianópolis, SC. Telefone/Fax (48)331.9984. E-mail: siqueira@mbox1.ufsc.br. 